\title{
FORRAGEAMENTO DE APIS MELLIFERA L. EM OITICICA (LICANIA RIGIDA)
}

THE FORAGING OF APIS MELLIFERA L. ON OITICICA (LICANIA RIGIDA)

Silva, R.A. ${ }^{1 \star}$, Fernandes, D. ${ }^{1}$, Lucena Bezerra, L. $^{1}$, Costa Silva, W.S. ${ }^{1}$ e Barreto de Lima, A. ${ }^{1}$

${ }^{1}$ Departamento de Letras e Ciências Agrárias do Centro de Ciências Humanas e Agrárias da Universidade Estadual da Paraíba. Catolé do Rocha. Paraíba. Brasil. *rosileneagra@hotmail.com

\section{PALAVRAS CHAVE ADICIONAIS}

Freqüência de visitas. Abelhas. Flores.

\section{RESUMO}

Com o objetivo de observar a freqüência de visitas de Apis mellifera L. em flores de oticica, verificando ainda o tipo de coleta realizada pelas abelhas ao longo do dia, esta pesquisa foi conduzida no Campus IV do Centro de Ciências Humanas e Agrárias da Universidade Estadual da Paraíba, localizado no município de Catolé do Rocha-PB. Para se determinar o número das visitas, o contagem foi feito no período de 07:00 as 17:00 horas, a cada dez minutos, durante seis dias. As abelhas forrageiam na oiticica néctar, apresentando um maior número de visitas nas flores localizadas à sombra e nas que receberam menor impacto dos ventos.

\section{SUMMARY}

This research was carried at Campus IV do Centro de Ciências Humanas e Agrárias da Universidade Estadual da Paraíba, Catolé do Rocha, Paraiba, Brazil, to study the foraging behavior of Apis mellifera L. on Licania rigida flowers along day. The number of visits that bees made to flowers from 07:00 to 17:00 hours, were recorded every 10 minutes, during six days. The results showed that honey bees foraged for nectar more frequently under shaded and wind protected parts.

\section{INTRODUÇÃO}

A oiticiqueira (Licania rigida) é uma planta perene, de grande porte e longevidade, oriunda do Brasil, encontrada de 50 até 500 $\mathrm{m}$ de altitude, nas aluviões marginais dos

Recibido:19-2-07. Aceptado: 6-3-07.

\section{AdDitional KEYWORDS}

Frequency of visits. Bees. Flowers.

rios e riachos, nativa, espalhada entre outras vegetações. Ramifica-se pouco acima do chão e a copa pode atingir até $15-20 \mathrm{~m}$ de circunferência, armazenando nutrientes no caule e nas raízes na forma de água, hidratos de carbono, ácidos orgânicos e outras substâncias, a fim de sobreviver os anos de seca. A inflorescência se dá em espigas racemosas, situadas nas pontas dos ramos, aparecendo no mês de junho até outubro. Com flores pequenas e hermafroditas agrupam-se em centenas, amareladas no seu interior, de 2 a 5 mm de diâmetro. Em geral uma flor fica aberta 4 dias, e o estigma torna-se muito úmido de madrugada. A floração é continua até 100 dias desde a primeira até a ultima flor. Quando as derradeiras flores são fecundadas, os primeiros frutinhos apresentam-se com cerca de $3 \mathrm{~cm}$. A abertura das flores coincide com a época mais seca do ano (Aboissa, 2006).

Na microrregião de Catolé do Rocha, localizada no estado da Paraíba - Brasil há uma grande densidade relativa de oiticica, o que caracteriza a região. No período em que a oiticica está florando, os apicultores realizam até três colheitas de mel, reiterando a sua importância como planta apícola nativa. Diante do exposto, objetivou verificar o forrageamento de abelhas Apis mellifera 
Tabela I. Freqüência média do número de abelhas Apis mellifera coletando néctar nas flores de oiticica no período de agosto a setembro de 2006. Catolé do Rocha, Paraíba, Brasil. (Average number of bees collecting nectar from oiticica flowers, from September to August. Catolé do Rocha, Paraíba, Brasil).

\begin{tabular}{|c|c|c|c|c|c|c|c|}
\hline $\begin{array}{l}\text { Horário } \\
\text { (manhã) }\end{array}$ & $n$ & $\begin{array}{l}\text { Freqüência } \\
\text { média }\end{array}$ & $\begin{array}{l}\text { Desvio } \\
\text { padrão }\end{array}$ & $\begin{array}{l}\text { Horário } \\
\text { (tarde) }\end{array}$ & $\mathrm{n}$ & $\begin{array}{l}\text { Freqüência } \\
\text { média }\end{array}$ & $\begin{array}{l}\text { Desvio } \\
\text { padrão }\end{array}$ \\
\hline 07:00 & 6 & 41 & 12,90 & $13: 00$ & 6 & 53 & 24,78 \\
\hline 07:10 & 6 & 47 & 17,06 & $13: 10$ & 6 & 51 & 31,58 \\
\hline $07: 20$ & 6 & 48 & 20,45 & $13: 20$ & 6 & 52 & 26,98 \\
\hline 07:30 & 6 & 46 & 18,67 & $13: 30$ & 6 & 52 & 31,01 \\
\hline $07: 40$ & 6 & 48 & 9,44 & $13: 40$ & 6 & 49 & 24,09 \\
\hline 07:50 & 6 & 52 & 8,98 & $13: 50$ & 6 & 39 & 23,30 \\
\hline 08:00 & 6 & 51 & 18,86 & $14: 00$ & 6 & 41 & 24,77 \\
\hline 08:10 & 6 & 51 & 16,99 & $14: 10$ & 6 & 42 & 30,01 \\
\hline $08: 20$ & 6 & 46 & 9,48 & $14: 20$ & 6 & 37 & 26,49 \\
\hline 08:30 & 6 & 45 & 10,43 & $14: 30$ & 6 & 43 & 22,03 \\
\hline 08:40 & 6 & 41 & 12,11 & $14: 40$ & 6 & 39 & 26,38 \\
\hline 08:50 & 6 & 36 & 12,89 & $14: 50$ & 6 & 40 & 23,31 \\
\hline 09:00 & 6 & 31 & 11,00 & $15: 00$ & 6 & 45 & 21,57 \\
\hline 09:10 & 6 & 26 & 10,07 & $15: 10$ & 6 & 44 & 23,95 \\
\hline 09:20 & 6 & 28 & 11,36 & $15: 20$ & 6 & 37 & 20,51 \\
\hline 09:30 & 6 & 29 & 11,87 & $15: 30$ & 6 & 33 & 25,34 \\
\hline 09:40 & 6 & 29 & 13,94 & $15: 40$ & 6 & 32 & 19,91 \\
\hline 09:50 & 6 & 27 & 14,68 & $15: 50$ & 6 & 29 & 17,43 \\
\hline $10: 00$ & 6 & 26 & 12,47 & $16: 00$ & 6 & 29 & 15,38 \\
\hline $10: 10$ & 6 & 26 & 11,02 & $16: 10$ & 6 & 29 & 15,97 \\
\hline $10: 20$ & 6 & 32 & 14,76 & $16: 20$ & 6 & 26 & 15,96 \\
\hline $10: 30$ & 6 & 35 & 17,38 & $16: 30$ & 6 & 23 & 13,02 \\
\hline $10: 40$ & 6 & 32 & 17,63 & $16: 40$ & 6 & 19 & 13,98 \\
\hline $10: 50$ & 6 & 31 & 15,77 & $16: 50$ & 6 & 16 & 7,92 \\
\hline $11: 00$ & 6 & 32 & 17,58 & $17: 00$ & 6 & 15 & 6,05 \\
\hline
\end{tabular}

em flores de oiticica, verificando ainda o tipo de coleta realizada pelas abelhas ao longo do dia.

\section{MATERIAISE MÉTODOS}

O estudo foi conduzido em plantas de oiticica (Licania rigida) em uma área do Campus IV do Centro de Ciências Humanas e Agrárias da Universidade Estadual da Paraíba(UEPB), localizada no município de Catolé do Rocha - PB, Brasil, a 272 m de altitude sob as coordenadas de latitude $6^{\circ} 20^{\prime} 38^{\prime \prime}$ O e longitude $37^{\circ} 44^{\prime} 48^{\prime \prime} \mathrm{O}$. O clima nesta região é do tipo Bsh-Semiárido, quente com chuvas de verão e, segundo a divisão do Estado da Paraíba em regiões bioclimáticas, possui bioclima 4bTh de seca média com 5 a 7 meses secos. Caracterizada por uma baixa pluviosidade (500 mm a 800 mm anuais), uma vegetação tipo caatinga hipoxerófila, nas áreas menos secas, e de caatinga hiperxerófila, nas áreas de seca mais acentuada e, temperatura média é de 26 a $27^{\circ} \mathrm{C}$ (CPRM, 2005).

O período de observação foi entre os meses de agosto e setembro de 2006, onde as oiticicas encontravam-se no pico de floração na região. Para se determinar a freqüência de visitas às flores e tipo de coleta realizada pelas abelhas, no decorrer do dia, foram obtidos por contagem, 10

Archivos de zootecnia vol. 59, núm. 227, p. 444. 
minutos em cada horário, das sete às 17 horas, com seis repetições, de acordo com a metodologia adotada por Malerbo-Souza etal. (2004).

\section{RESULTADOSEDISCUSSÃO}

O período de floração da oiticica na área experimental foi de agosto a outubro de 2006, onde o pico de floração foi observado no mês de setembro, período em que foi realizado o experimento. O resultado da análise de freqüência das abelhas na oiticica pode ser observado na tabela I.

A freqüência de visitas das abelhas às flores de oiticica foi maior na primeira hora de cada turno (7:00 as 8:00 e 13:00 as 14:00), seguida de uma diminuição do número de abelhas visitantes após a primeira hora de observação, a qual pode ser explicada pela diminuição do fluxo néctar, após intensa coleta pelas abelhas. Verificou-se ainda, que as abelhas apresentaram preferência apenas para coleta de néctar, sendo mais freqüentes no horário da tarde, e que com o entardecer ocorreu uma diminuição considerável no número de visitantes. Além disso, constatou-se que as flores sombreadas e as que receberam menor impacto do vento, foram mais visitadas que as expostas ao sol e ao vento. Tendo em vista que a tempera-

\section{BIBLIOGRAFIA}

Aboissa. 2006. Oiticica. http://www.aboissa com.br/oiticica/oiticica7.htm. (10/09/06).

CPRM . 2005. Serviço Geológico do Brasil. Projeto cadastro de fontes de abastecimento por água subterrânea. Diagnóstico do município de Catolé do Rocha, estado da Paraíba/ Organizado [por] João de Castro Mascarenhas, Breno Augusto Beltrão, Luiz Carlos de Souza Junior, Franklin de Morais, Vanildo Almeida Mendes, Jorge Luiz Fortunato de Miranda. CPRM/PRODEEM. Recife. Generalidades. 2006. http://www.ufv.br/dbg/bee/ tura elevada é importante na secreção de néctar porque torna mais permeável a membrana dos nectários, aumentando o poder solvente da água e acelerando as reações químicas que se produzem no vegetal, enquanto que a ausência de ventos mantém a secreção de néctar constante (Generalidades, 2006), estes fatores podem explicar o comportamento das abelhas nas flores.

Malerbo-Souza et al. (2004), estudando o comportamento das abelhas A. mellifera nas flores da jabuticabeiras observaram que a freqüência dessas abelhas foi maior no inicio do dia, quando o ar estava mais úmido. Segundo Paulino et al. (2003), o volume e a concentração do néctar podem ser afetados pelas visitas de abelhas e pelo microclima, sendo positivamente correlacionados com as visitas das abelhas.

\section{CONCLUSÕES}

A freqüência das abelhas Apis mellifera nas flores da oiticica é maior nas primeiras horas de cada período quando há sombreamento das flores e menor incidência de ventos fortes.

As flores de oiticica são atrativas para as abelhas para a coleta de néctar, uma vez que esta planta apresenta potencial considerável para produção de mel.

flora.htm (12/09/06)

Malerbo-Souza, D.T., Nogueira-Couto, R.H. e Toledo, A.A. 2004. Abelhas visitantes nas flores da jabuticabeira (Myrciaria cauliflora Berg.) e produção de frutos. Acta Scientiarum. Anim. Sci., 26: 1-4.

Paulino, F.D.G., Marchini, L.C. e Silva, L.A.C. 2003. Comportamento forrageiro de Apis mellifera L. 1758 em panículas da nogueira macadâmia (Macadamia integrifólia Maiden \& Betche). Rev. Ciência Agronômica, 34: 5-9. 